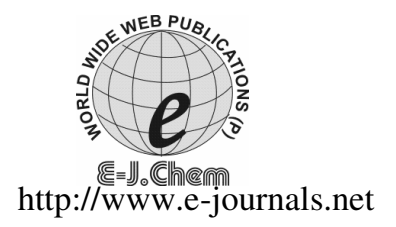

ISSN: 0973-4945; CODEN ECJHAO

E-Journal of Chemistry

2012, 9(1), 282-288

\title{
Effect of Reaction Temperature on Size and Optical Properties of $\mathrm{NiTiO}_{3} \mathrm{Nanoparticles}$
}

\author{
R.VIJAYALAKSHMI* and V.RAJENDRAN \\ Department of Physics, \\ Presidency College, Chennai, Tamilnadu, India \\ viji2302@gmail.com
}

Received 28 April 2011; Revised 5 July 2011; Accepted 30 July 2011

\begin{abstract}
Nickel titanate $\left(\mathrm{NiTiO}_{3}\right)$ nanoparticles were successfully prepared by wet-chemical method, using nickel acetate and titanium(IV) isopropoxide as $\mathrm{Ni}$, Ti sources and citric acid as complexing reagent. The gel was calcined at different temperatures from $500-700{ }^{\circ} \mathrm{C}$. Results of thermogravimetric analysis (TGA) are given. Fourier transform infrared spectrometry (FTIR), X-ray diffraction (XRD), Scanning electron microscopy (SEM),transmission electron microscopy (TEM), ultraviolet (UV) spectroscopy, vibrating sample magnetometer (VSM) were used to characterize the crystallization process, particle size, morphology, optical and magnetic properties of the calcined nanoparticles. TEM result reveals that the $\mathrm{NiTiO}_{3}$ was homogeneous and hexagon morphology with the grain size of 30-70 nm. The band gap values of the $\mathrm{NiTiO}_{3}$ nanoparticles were calculated to be $3.43,3.39$ and $3.31 \mathrm{eV}$. The magnetic property was confirmed that the $\mathrm{NiTiO}_{3}$ nanoparticles of super paramagnetic behavior in nature. Our results suggested that the temperature plays an important role in the particle size effect of nanocrystalline $\mathrm{NiTiO}_{3}$.
\end{abstract}

Keywords: Nanoparticle, X-ray diffraction, Optical properties, Morphology,

\section{Introduction}

The metal titanates based oxides including metals, such as nickel, cobalt, ferrite, zinc, copper and lead are universally known as inorganic functional materials with wide applications. For example, they are applicable for industries, such as semiconductor rectifiers, electrodes of solid oxide fuel cell, metal-air barrier, hydro carbonate catalyzers, color mixtures of surface coating and gas sensing devices, etc. ${ }^{1-5}$.

$\mathrm{NiTiO}_{3}$ belong to the ilmenite structure. $\mathrm{Ni}$ and $\mathrm{Ti}$ atoms prefer octahedral coordination with alternating cation layers occupied by $\mathrm{Ni}$ and $\mathrm{Ti}$ alone ${ }^{6}$. On conventional solid state reaction, the preparation of $\mathrm{NiTiO}_{3}$ nanoparticles requires high-temperature treatment over $1000{ }^{\circ} \mathrm{C}$ for an extended period until intermediate phases disappear. The traditional preparation 
methods of $\mathrm{NiTiO}_{3}$ can produce large $\mathrm{NiTiO}_{3}$ nanoparticles with uncontrolled morphologies due to their inherent problems such as high reaction temperature, heterogeneous solid phase reaction etc. By contrast with the traditional methods, the wet-chemical synthesis techniques, including sol-gel, sol-precipitation, combustion synthesis, chemical coprecipitation and hydrothermal synthesis, offer many distinctive advantages over traditional methods in the production of powders. There are few reports available regarding chemical synthesis of $\mathrm{NiTiO}_{3}$ nanoparticles by citrate, maleate and propionic acid methods ${ }^{7-12}$. Thus, it is a meaningful work some routes at a low temperature to prepare ultra-fine particles of $\mathrm{NiTiO}_{3}$ with a controlled morphology, narrow size distribution and high purity.

As a matter of fact, metal alkoxides and metal acetates are both easily dissolved in certain solvents such as methanol, ethanol, iso-proponal, ethylene and 2-methoxy ethanol ${ }^{10}$. In this study, we chose one typical wet-chemical synthesis method, citric acid complex, to try to prepare pure $\mathrm{NiTiO}_{3}$ nanoparticles from titanium(IV) isopropoxide and nickel acetate. Citric acid and methanol $\left(\mathrm{CH}_{3} \mathrm{OH}\right)$ are used as the chelating agent and a solvent. Moreover, this synthesis process is easily controlled and convenient in comparison with other methods. The formation of process and structural characterization of $\mathrm{NiTiO}_{3}$ phase have been investigated by thermogravimetric analysis (TGA), X-ray diffraction (XRD), fourier transform infrared (FTIR), scanning electron microscope (SEM), transmission electron microscope (TEM), ultra-violet vis absorption (UV) and vibrating sample magnetometer (VSM).

\section{Experimental}

$\mathrm{NiTiO}_{3}$ nanoparticles were prepared along a synthetic procedure as summarized in Figure 1. A stoichiometric amount of nickel acetate and titanium(IV) isopropoxide with the cationic ratio of $\mathrm{Ni}$ : Ti $=1: 1$ were separately dissolved in methanol. Citric acid was then put into the $\mathrm{Ti}^{4+}$ solution, and it kept in transparency. While the $\mathrm{Ni}^{2+}$ solution was also mixed with the above-mentioned glassy solution, the precipitates came out. They were further heated at $90{ }^{\circ} \mathrm{C}$ in an oven for $12 \mathrm{~h}$ to remove the excess solvent and the agglomerate precursors in light green color were formed. After the organic precursor was calcined at $500-700{ }^{\circ} \mathrm{C}$ for $3 \mathrm{~h}$, the phase-pured yellow $\mathrm{NiTiO}_{3}$ nanoparticles were finally obtained after furnace cooling to room temperature.

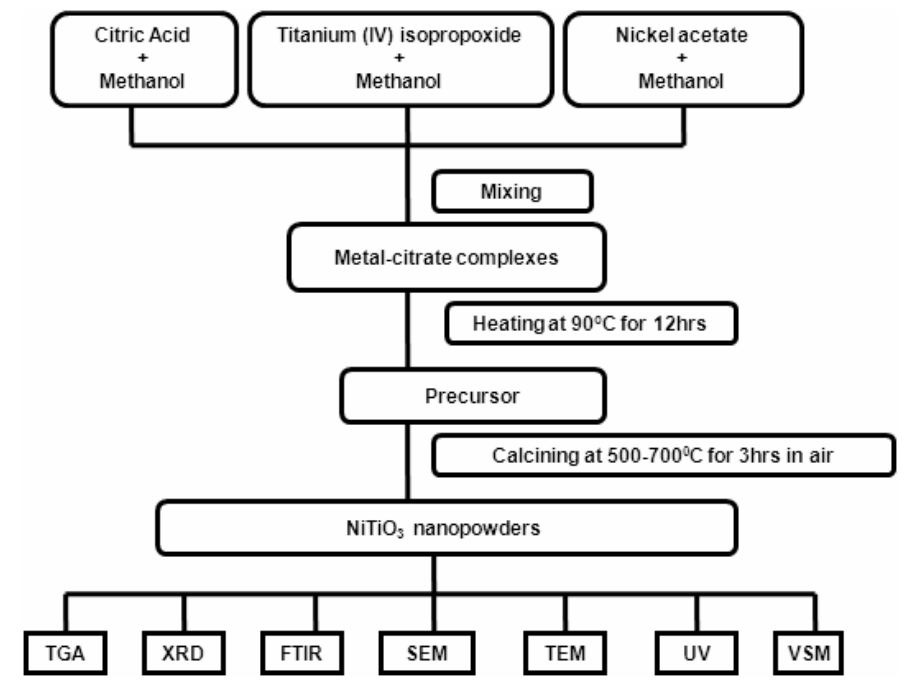

Figure 1. Flow chart of the synthesis of $\mathrm{NiTiO}_{3}$ nanoparticles by the wet chemical method 
The size and crystalline phase of $\mathrm{NiTiO}_{3}$ was determined using X-ray diffractometer Schimadzu model: XRD 6000 with $\mathrm{CuK} \alpha$ radiation in the range $20-70^{\circ}(\lambda=0.154 \mathrm{~nm})$. Thermogravimetric analysis (TGA) was carried out with a Shimadzu 50-TG-DTA at a heating rate of $20{ }^{\circ} \mathrm{C} / \mathrm{min}$. The FT-IR spectrum of the samples was taken using a FTIR model Bruker IFS 66W spectrometer. UV-Vis absorption spectra of $\mathrm{NiTiO}_{3}$ were recorded using a Varian Cary 5E spectrophotometer at room temperature in the range of $200-1000 \mathrm{~nm}$. The surface morphologies of as-prepared $\mathrm{NiTiO}_{3}$ the products were studied using the Hitachi S-4500 Scanning Electron Microscope. Transmission Electron Microscope (TEM) studies was taken using a model JEOL-2010 microscope with an accelerating voltage of $100 \mathrm{kV}$. The magnetic measurement was carried out in a Vibrating Sample Magnetometer (VSM: BHV-55, Riken Japan) at room temperature.

\section{Results and Discussion}

Figure 2 shows the TG curve of the citrate complex dried at $90{ }^{\circ} \mathrm{C}$ for $12 \mathrm{~h}$. The weight loss below $100{ }^{\circ} \mathrm{C}$ was assigned to desorption of water. The weight loss between $\sim 200$ and $\sim 450{ }^{\circ} \mathrm{C}$ was due to desorption of organic components in the precursor. At temperature above $450{ }^{\circ} \mathrm{C}$ no further weight loss was observed, which indicates complete removal of organic residues and the formation of crystalline $\mathrm{NiTiO}_{3}$. Thus, the minimum firing temperature to obtain organic-free precursor can be determined above $450{ }^{\circ} \mathrm{C}$. Since the decomposition seems to have several steps such as:

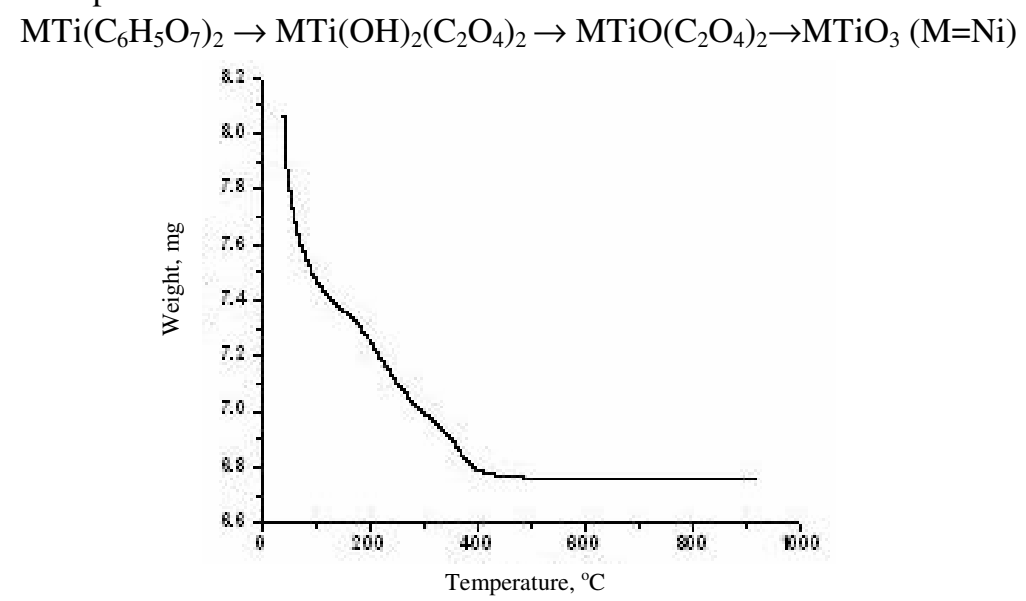

Figure 2. TGA Curve of the citrate complex dried at $90{ }^{\circ} \mathrm{C}$ for $12 \mathrm{~h}$

Figure 3(a-c) shows the XRD patterns of the $\mathrm{NiTiO}_{3}$ nanoparticles calcined at different temperatures $\left(500,600\right.$ and $\left.700{ }^{\circ} \mathrm{C}\right)$. At $500{ }^{\circ} \mathrm{C}$, the crystallization of rhombohedral nickel titanate phase began along with traces of rutile $\left({ }^{\mathbf{R}}\right.$ marked peaks) and anatase phase $\left({ }^{\mathbf{A}}\right.$ marked peaks; Figure 2a). Further, by increasing the calcination temperature to $600{ }^{\circ} \mathrm{C}$, both anatase and rutile phase was decreased with an increase in the intensity of $\mathrm{NiTiO}_{3}$ phase (Figure 2b). The $\mathrm{NiTiO}_{3}$ nanoparticles were further calcined at $700{ }^{\circ} \mathrm{C}$ (Figure 2c). However, at this temperature, the nanoparticles displayed sharp and intense peaks indicating crystalline rhombohedral $\mathrm{NiTiO}_{3}$ phase. All the peaks corresponding to rhombohedral phase were well matched with database in JCPDS (File No. 33-960). According to the Debye Scherrer's formula, $D=k \lambda / \beta \cos \theta$ where $D$ is the average size of the particles, $k=0.9, \lambda$ is the $\mathrm{X}$-ray wavelength $(0.154 \mathrm{~nm}$ for $\mathrm{CuK} \alpha), \quad \beta$ is the full width at half maximum of the diffracted peak (FWHM) and $\theta$ is the Bragg diffraction angle ${ }^{13}$. The crystalline sizes of 
$\mathrm{NiTiO}_{3}$ were calculated to be 30,45 and $65 \mathrm{~nm}$ for the samples prepared at temperatures 500, 600 and $700{ }^{\circ} \mathrm{C}$ respectively. The crystalline sizes were reveals that clearly with decreasing calcination temperature, the crystalline size also decrease.

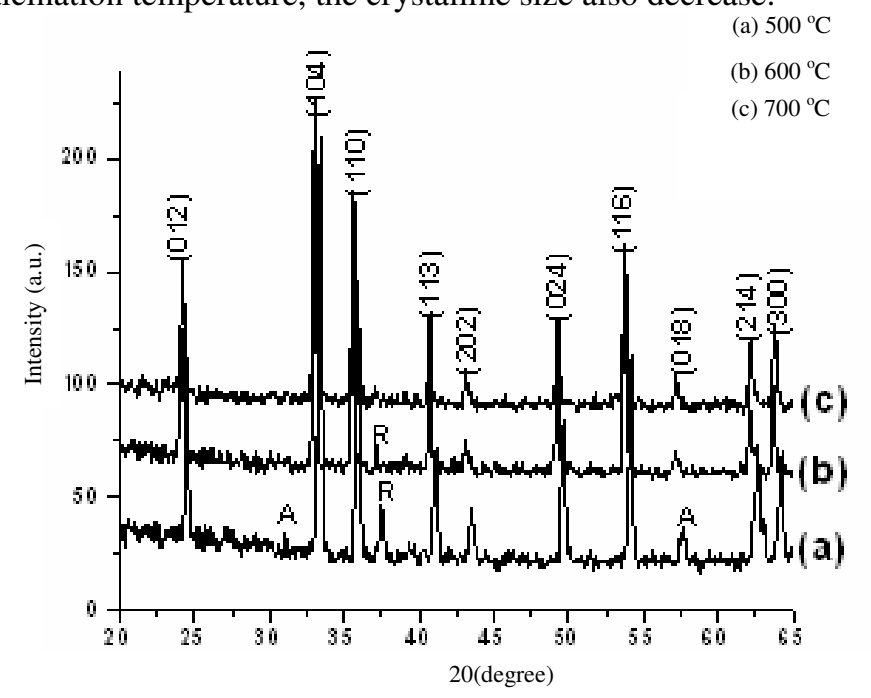

Figure 3(a-c). XRD patterns of the $\mathrm{NiTiO}_{3}$ nanoparticles calcined at different temperatures 500,600 and $700{ }^{\circ} \mathrm{C}$

Figure 4 shows the FT-IR spectra of as-synthesized $\mathrm{NiTiO}_{3}$ nanoparticles calcined at 500 and $700{ }^{\circ} \mathrm{C}$. It is clear from Figure 4a that the weak bands at 3391 and $1615 \mathrm{~cm}^{-1}$ were assigned to the stretching vibrations of surface hydroxyl $(-\mathrm{OH})$ groups and another band around $1280 \mathrm{~cm}^{-1}$ was due to the bending vibration of the $\mathrm{H}-\mathrm{O}-\mathrm{H}$ bonds. However, as the temperature increased (Figure 4b), the stretching vibration of $-\mathrm{OH}$ and $\mathrm{H}-\mathrm{O}-\mathrm{H}$ bands were completely disappeared, which is consistent with the TGA results. The very strong bands appeared at 617 and $690 \mathrm{~cm}^{-1}$ are due to the stretching of Ti-O bond and bending of O-Ti-O bond meanwhile the absorption at $547 \mathrm{~cm}^{-1}$ is result from Ni-O bond, which indicating ${ }^{14}$ the formation of $\mathrm{NiTiO}_{3}$.

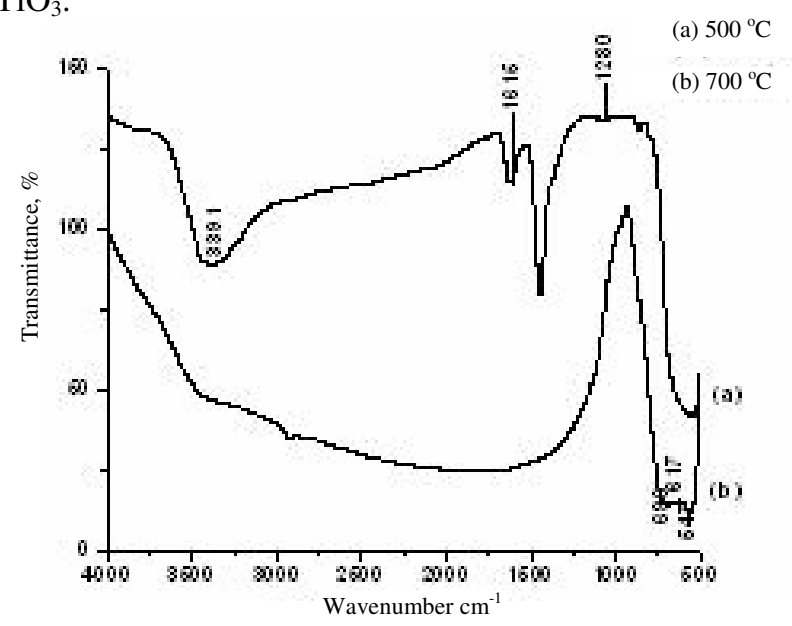

Figure 4. (a-b) FT-IR spectra of as-synthesized $\mathrm{NiTiO}_{3}$ nanoparticles calcined at 500 and $700{ }^{\circ} \mathrm{C}$ 
Figure 5(ab) represents the SEM morphologies of the as-synthesized $\mathrm{NiTiO}_{3}$ nanoparticles calcined at 500 and $700{ }^{\circ} \mathrm{C}$. The SEM images clearly shows homogeneous, uniform crystal size and remarkably different morphologies for the $\mathrm{NiTiO}_{3}$ nanoparticles. Spheroid-like morphology was observed for the sample calcined at $500{ }^{\circ} \mathrm{C}$ (Figure 5a). Whereas (Figure 5b) an ellipsoid-like morphology was obtained when the temperature increased to $700{ }^{\circ} \mathrm{C}$, which is well accord with the XRD results. And also it is smaller than those prepared by co-precipitation method ${ }^{15}$ (about $90 \mathrm{~nm}$ ) and solid state reaction method (sintered at above $1000{ }^{0} \mathrm{C}$ with comparatively larger particle size about $1 \mu \mathrm{m}$ ) ${ }^{16}$.
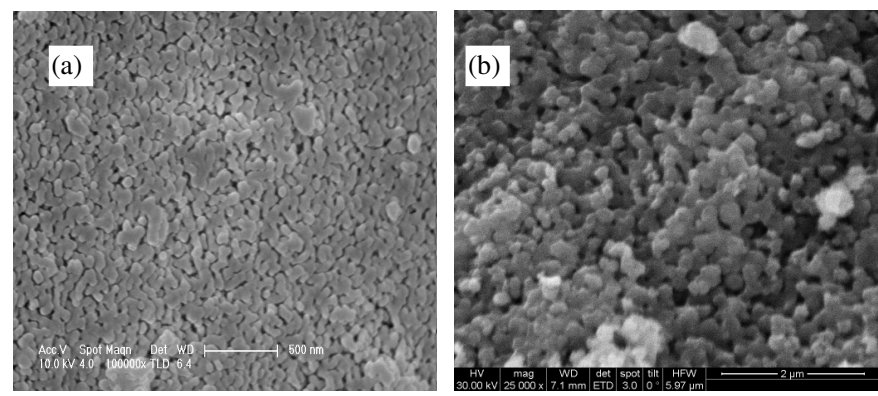

Figure 5(a-b). SEM morphologies of the as-synthesized $\mathrm{NiTiO}_{3}$ nanoparticles calcined at 500 and $700{ }^{\circ} \mathrm{C}$

The morphologies and particle sizes were further investigated by TEM. Figure 6a shows the TEM image of the as-prepared $\mathrm{NiTiO}_{3}$ nanoparticles calcined at $500{ }^{\circ} \mathrm{C}$. The obvious rings of selective area electron diffraction (SAED) in the inset of Figure 6a indicate that all the products are polycrystalline. Figure 6a shows $\mathrm{NiTiO}_{3}$ nanoparticle with hexagon morphology of size about $\sim 30-40 \mathrm{~nm}$. Most of the nanoparticles were well separated although some of them partially aggregated. Figure $6 \mathrm{~b}$ reveals TEM pattern of sample calcined at $700{ }^{\circ} \mathrm{C}$. Comparing to that of $500{ }^{\circ} \mathrm{C}$, crystalline size of the products were increased to $60-70 \mathrm{~nm}$. Moreover, the particle size of the samples obtained from TEM patterns are quite similar to those calculated from Scherrer's equation.

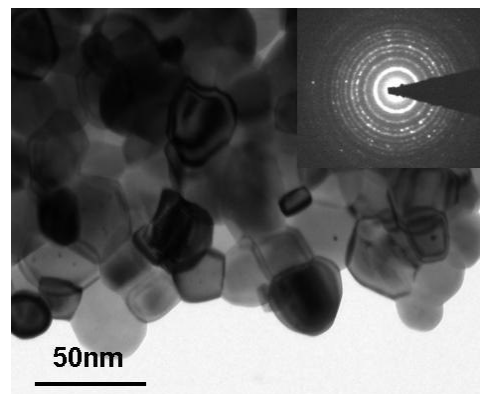

Figure 6a. TEM image of the as-prepared $\mathrm{NiTiO}_{3}$ nanoparticles calcined at $500{ }^{\circ} \mathrm{C}$.

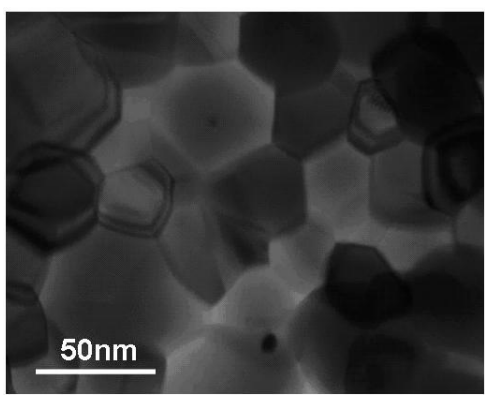

Figure 6b. TEM image of the as-prepared $\mathrm{NiTiO}_{3}$ nanoparticles calcined at $700{ }^{\circ} \mathrm{C}$

The room temperature UV-Visible spectrum (Figure 7a) of the as-prepared $\mathrm{NiTiO}_{3}$ nanoparticles calcined at $500{ }^{\circ} \mathrm{C}$ has the absorption edge is at $364 \mathrm{~nm}$, which is smaller than the band edge observed at 370 and $376 \mathrm{~nm}$ for calcined at 600 and $700{ }^{\circ} \mathrm{C}$ as shown in Figure $7 \mathrm{~b} \&$ c. In all the cases, blue shifts were observed. Considering the blue shifts of the absorption positions from the bulk $\mathrm{NiTiO}_{3}$, the absorption onsets of the present samples can be assigned to the direct transition of electron in the $\mathrm{NiTiO}_{3}$ crystal ${ }^{17}$. The corresponding bandgap energies 
can be calculated to be $3.43,3.39$ and $3.31 \mathrm{eV}$ and are larger than the bulk $\mathrm{NiTiO}_{3}(3.2 \mathrm{eV})$. The increasing trends of the band gap energy upon the decreasing particle size are well presented for the quantum confinement effect ${ }^{18}$.

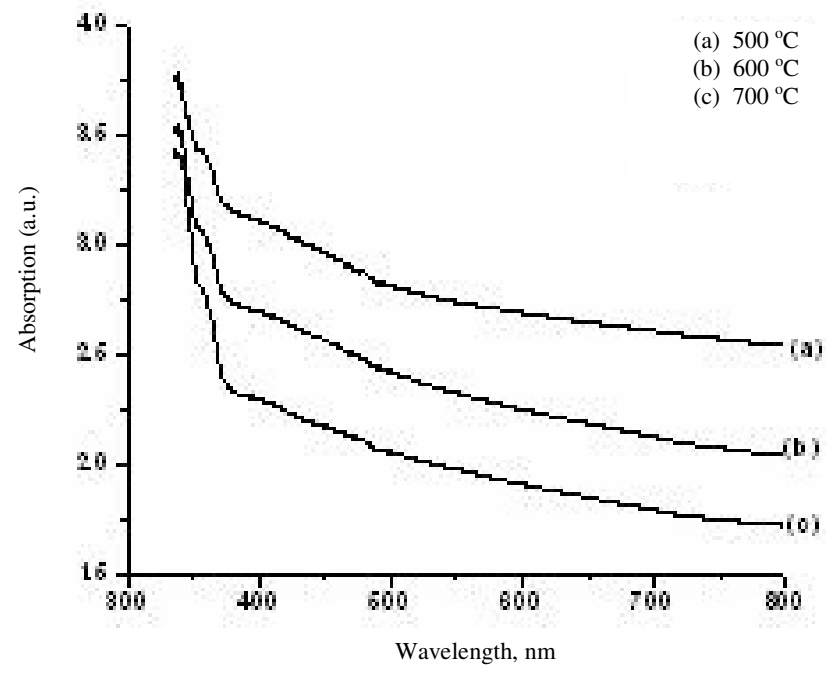

Figure 7. UV-Vis absorption spectra of the as-prepared $\mathrm{NiTiO}_{3}$ nanoparticles calcined at $500{ }^{\circ} \mathrm{C}$.

Figure 8 shows the hysteresis loops of $\mathrm{NiTiO}_{3}$ nanoparticles at $500{ }^{\circ} \mathrm{C}$. From the result, it was found that the saturated magnetization $\left(\mathrm{M}_{\mathrm{s}}\right)$ of the fabricated $\mathrm{NiTiO}_{3}$ nanoparticles was $15 \mathrm{emu} / \mathrm{g}$ and its saturated magnetic strength was $2760 \mathrm{Oe}$. In addition, the experiment show that is residual magnetism and coercive force $(\mathrm{Hc})$ was close to 31.85 , confirming that the magnetic particle was super paramagnetic particle. In other words, when the particle is small enough, and the anisotropy energy is too small to be identical with the heat motion, the direction of magnetization would no longer be fixed and the direction of easy magnetization would change irregularly, causing the phenomenon of super para magnetism.

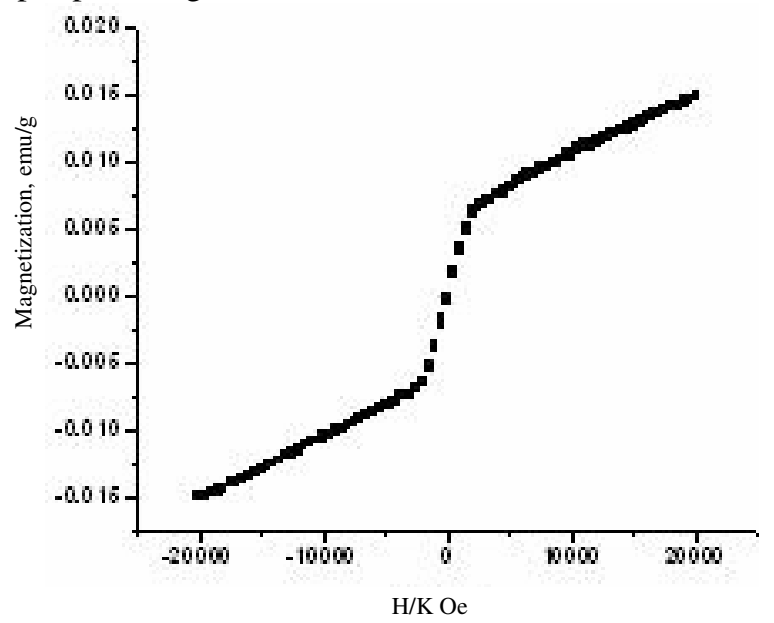

Figure 8. Magnetic property of the as-prepared $\mathrm{NiTiO}_{3}$ nanoparticles calcined at $500{ }^{\circ} \mathrm{C}$ 


\section{Conclusion}

This study has demonstrated the feasibility of synthesis of pure $\mathrm{NiTiO}_{3}$ nanoparticles using wet-chemical synthesis route, metal-citrate complex at different temperatures $(500,600$ and $700{ }^{\circ} \mathrm{C}$ ). The TGA analysis indicates that the crystallization temperature of $\mathrm{NiTiO}_{3}$ was above $450{ }^{\circ} \mathrm{C}$. The chemical structure information of the products was studied by Fourier Transform Infrared (FT-IR) spectroscopy. Well crystallized $\mathrm{NiTiO}_{3}$ nanoparticles could be synthesized at $700{ }^{\circ} \mathrm{C}$ for $3 \mathrm{~h}$. The microstructures of $\mathrm{NiTiO}_{3}$ nanoparticles have been evaluated using SEM and TEM and the grain sizes are shown to vary between $\sim 30-70 \mathrm{~nm}$. The significant optical properties of this material may be very interesting for further application on photo catalyst. The temperature can affect the particle size; the decreasing trends of temperature upon the decreasing particle size are well presented for the assynthesized $\mathrm{NiTiO}_{3}$ nanoparticles. The magnetic property was studied using a vibrating sample magnetometer. We hope that the procedure mentioned in the experimental section can be a suitable route for the high-yield synthesis of $\mathrm{NiTiO}_{3}$ nanoparticles.

\section{Acknowledgement}

The authors are grateful to the University Grant Commission, for extending financial assistance to carry out this work.

\section{References}

1. Harris Q J, Phys Rev Lett., 1997, 78, 346.

2. Fisch R, Phys Rev B., 1995, 51, 11507.

3. Phani A R and Santucki S, Mater Lett., 2001, 396, 1.

4. Ming Chiang Y, Dumbar Birnie III, David Kingery W, Physical Ceramics, John Wiley \& Sons Inc., New York, 1996, 34.

5. Taguchi H, Matsuda D, Nagou M, Tanihara K and Miyamota Y, J Am Ceram Soc., 1992, 75, 201.

6. Lerch M, Boysen H, Nerde R, Frey F and Laqua W, J Phys Chem Solids., 1992, 53, 1153.

7. Chu F, Liu X Q, Wang G Z and Mong G Y, Mater Res Bull., 1999, 34, 1789.

8. Vadivel Murugan A, Violet Samuel Y, Navale Sc and Ravi V, Mater Lett. 2006, 60, 1791.

9. Marcilly C, Courty P and Delmon B J, J Am Ceram Soc., 1970, 53, 56.

10. Gaikwas S P, Dhesphande S B, Khollam Y, Samuel Y and Ravi V, Mater Lett., 2004, $\mathbf{5 8}, 3474$.

11. Taylor D J, Fleig P E and Page R A, Thin Solid Films, 2002, 408, 104.

12. Dharmaraj N, Park H C, Kim C K, Kin H Y and Lee D R, Mater Chem Phys., 2004, 87, 5.

13. SharmaY K, Kharkwal M, Uma S and Nagarajan R, Polyhedron, 2009, 28, 579.

14. Docuff S, Henry M, Sanchez C and Livage J, J Non-Cryst Solids, 1987, 89,206.

15. Dharmaraj N, Park H C, Kim C K, Kim H Y and Lee D R, Mater Chem Phys., 2004, 87, 5 .

16. Tietz F, Dias F J, Dubiel B and Penkalla H J, Mater Sci Eng B, 1999, 68, 35.

17. Zhou G W, Chen D R and Xu G Y, Acta Chimico Sinica, 2005, 20, 1971.

18. Zhou L, Liu X J, Zhang S Y, Wang J C and Zhang L D, J Nanjing University Natural Science, 1997, 33, 32. 


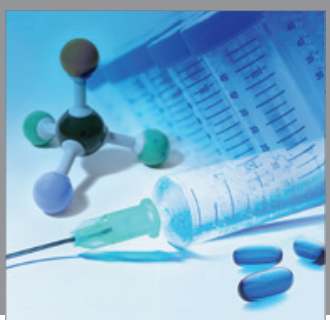

International Journal of

Medicinal Chemistry

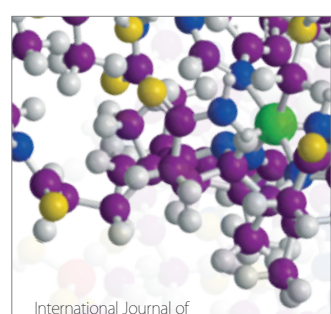

Carbohydrate Chemistry

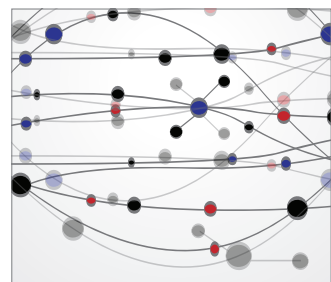

The Scientific World Journal
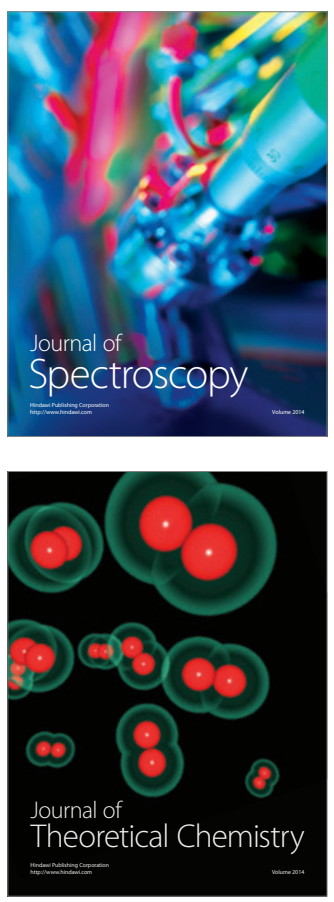
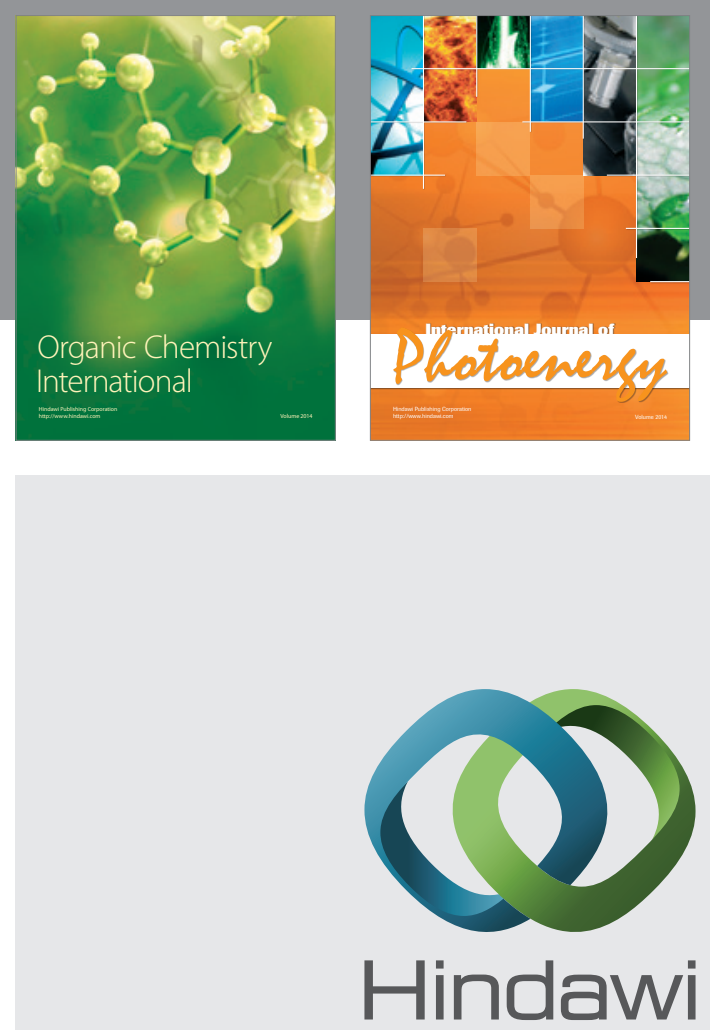

Submit your manuscripts at

http://www.hindawi.com
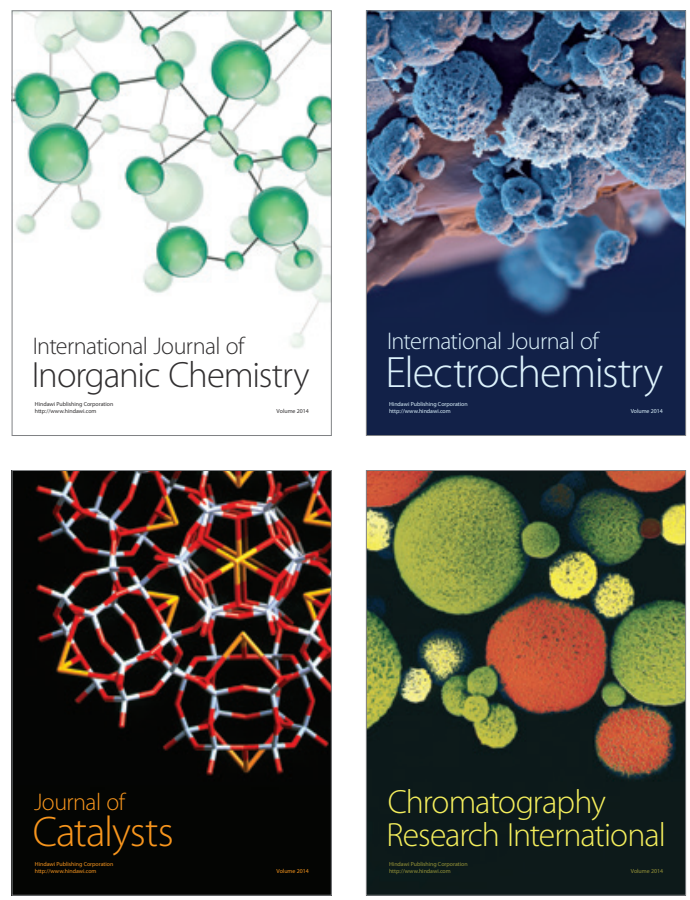
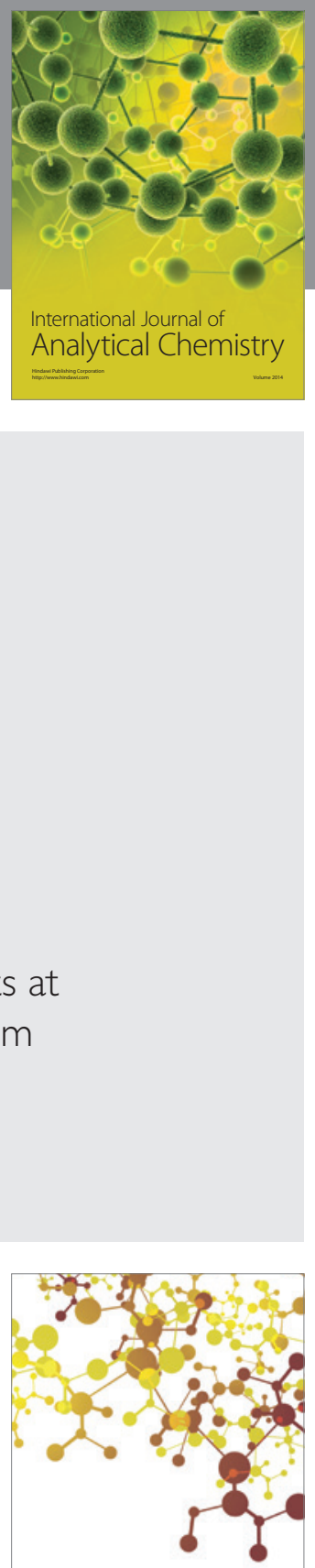

Journal of

Applied Chemistry
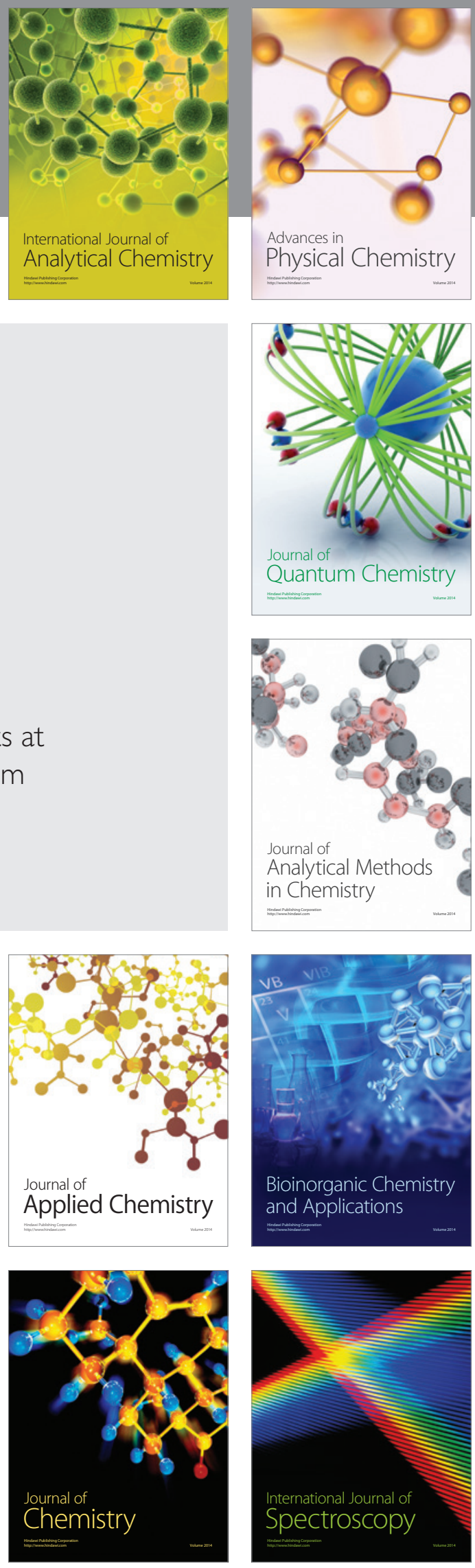